\title{
The status of China's Golf Club practitioners and revelation of relevant professional education
}

\author{
Li Dan ${ }^{1, \text { a }}$, Liu Tian ${ }^{2, b}$ \\ ${ }^{1}$ Hunan International Economics University Sport Department, Changsha Hunan 410205, China \\ ${ }^{2}$ Hunan International Economics University Sport Department, Changsha Hunan 410205, China
}

Keywords: Soccer Robot; Mechanical Analysis; Optimal Design

\begin{abstract}
Golf return with a new attitude after centennial drift and in dire need of manpower, material resources and policy support to improve the level of competitive and popularity. So many problems exist in practitioners such as high attrition rates, inexperienced managers,the low quality of employees that the serious consequence of development of the golf industry off the right track, years of losses and so on. This research learns from authoritative survey data and analysis the status of practitioners as a beginner to find out the course of those problems. Research from the perspective of education suggest that personnel training should be market-oriented make training mode varied and do well with career planning.
\end{abstract}

Golf has undergone there period in China from 1986 till now, which is the enlightenment of Zhong Shan Hot spring Golf Course, the development of Guan Lan Golf Course in Shenzhen and the time of prosperity after SARS. Until the end of the year 2012, there are 477 golf facilities and 10570 golf holes, which amount to 587 18-holed golf courses. They are distributed in 29 provinces, autonomous regions and municipalities. Golf clubs practitioners act as the main part of golf practitioners, covering the working staff in golf clubs, clubs, the affiliated hotels of golf courses and golf ranges as well as highly associated intermediary personnel, which accounts for 90 percent of the overall golf practitioners. As the main practitioners in the golf profession, the quantity and quality of club practitioners affect the healthy and sustainable development of the whole golf industry directly.

1. The constitution of golf club practitioners

"People-oriented" is the requirement of knowledge-driven economy age and modern society democratic, civilization development. Hunan resource is the first resource of economy development ${ }^{[1]}$. Golf club as a big entity, is the main carrier of golf industry development.

1.1 Make general personnel framework in enterprises as a clue

As an entity, golf club is no different from other enterprises in personnel framework, following conventional organization personnel principle, which, under the premise that tasks and responsibilities are closely related, and then recruit employees and set a team. According to authoritative statistics, equipment in every 18-holed golf course has a capacity of about 500 related personnel, thus the number of golf practitioners in our country should be about 200 thousand ${ }^{\text {[2] }}$. Golf practitioners are divided to different level, sharing different range of work and act in accordance with strong hierarchical sense.

1.2 Make the related staff who develop the core business of the club the dominant force

Golf club is a profit-making economical organization that mainly makes profit by renting the golf course in a unit time. Because of the high costs of golf courses construction, high taxation and the irreversibility of time, the products of clubs are high-valued and rare. Among this, the service of caddy, the sales of membership and the preservation of the law are the important insurance of the high quality of products enjoyed by customers ${ }^{[3]}$. They are the core business of a club. The placement of related functional divisions in a club concentrates on the core business of the club. In the sports department where staff serves the customer directly, caddies account for half number of the club employees. The maintenance done by golf lawn maintenance department contributes to the quality of club product, while the sales department promotes and advertises the product and service 
club. All the three departments have become the core business of club, assembling more than seventy percent professionals.

1.3 Departments set up under the principle of conciseness

Most clubs which emphasize on conciseness play the role of affiliated industry of some entity, such as the facilities of resorts, real estates and affiliated industries. Investors managing golf facilities aim at improving the business status and value of their entity enterprises, not making it the main industry. So when setting up departments, maintaining the ordinary operation is their principle, generally only golf lawn maintenance department (the maintenance for the course facilities), sales department (for reception) and sports department (playing golf service) are set up.

2. The status and potential problems with club practitioners

2.1 General analysis

\subsubsection{Age distribution}

According to the research of Chao Xiang Group, the working group in club is generally young, those who are under 30 accounts for 60 percent. (Refer to chart1)

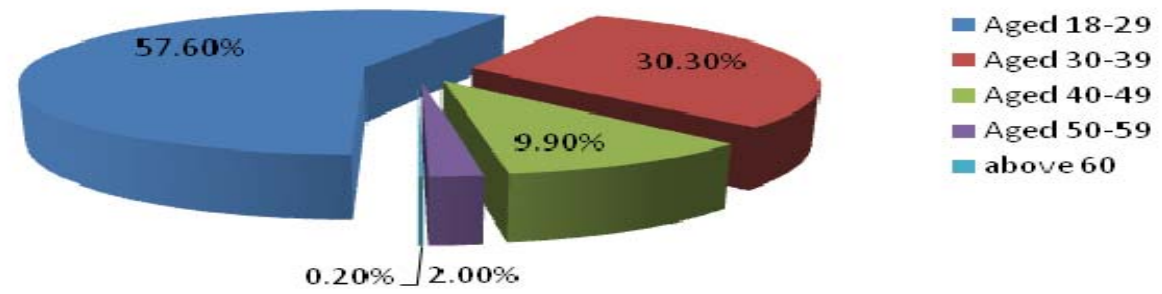

chart1 Distribution of years devoted to age

The time golf club employee spent in the career, the category of their working post and working experience will influence the confidence of practitioners, and thus determine the industry evaluation of every practitioner. Education background:Based on the research on the academic background of practitioners and professional background, people with high school degree rank first with a percentage of 35.4 percent. As to the aspect of professional background, management, agroforestry and sports account for certain percentage. (Refer to chart 2)
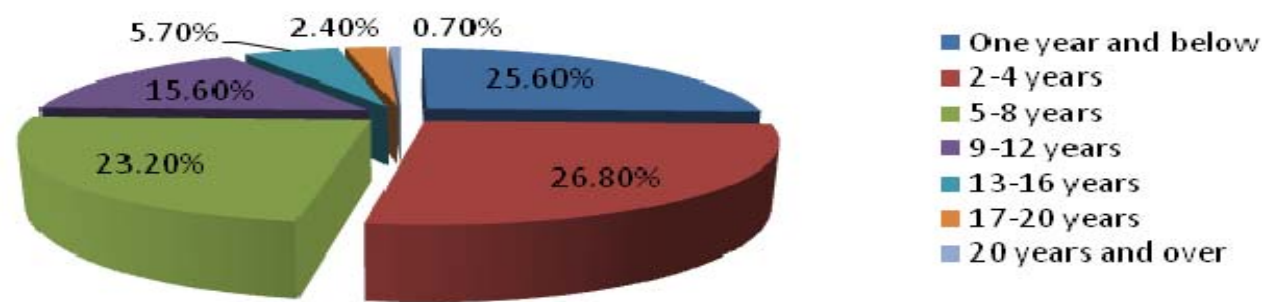

Chart 2 Distribution of years devoted to career

2.2 Status analysis of golf club management level

The management level lies between the decision-making level and executive level, playing the role of communicating the messages from the superior level and gathering information from the junior staff. It is the main body of golf club operation management, and it includes club general manager, vice-general manager, executive director and different department managers, etc. They are in charge of the supervision of the operation, management, maintenance, personnel and administration, the making of rules and regulations of different department in club and also the supervision of the execution, thus become the most important power in the club operation. In 2012, more than ninety percent of managers have an education background of junior college or higher education. Among them, 36.6 percent managers receive an undergraduate education, and only 26.9 percent have received postgraduate education. But sixty percent of the managing staff in other post received junior college education, and the major share nearly no similarity of their job.

2.3 Status analysis of executive level in club

The executive level covers the grass roots post of most clubs. They are the foundation of the 
development of club business. Caddy is the representative of grass roots level, accounts for almost fifty percent of the grass roots post, so we take the data in the sample survey focused on the caddy group to review the analyze the status of executive level. Caddies are called the spirits of the golf course, and also the strategist of the golf player. They are a very young golf practitioner team. Nearly ninety percent he interviewed caddies are aged between 18 and 29, only ten percent aged between 30 and 39. The survey on their education background shows that 65 percent caddies received an education of high school education and below this level, thirty percent possess undergraduate degree. In the research of job satisfaction degree of this group of people, is shows that 37.8 percent of them are satisfied, 43.8 percent feel just acceptable, nearly twenty percent are unsatisfied, which reflects on the high turnover rate of caddies is the priority of club management.

3. Current problem analysis towards golf practitioner group

3.1 The mobility of practitioners is very high, lacking the sense of belonging is common

The related industry including products used in golf course, golf clubs and the sales of costume, the tournament and media, etc. The number of practitioner rise from less than 200 people to 140 thousand nowadays. While take a look at the practitioners, lack of the sense of identity to the company (the club), frequent job-hopping in employees, resignation and career exchange are commonly existed. Practitioners whose cycle for changing career is less than two years right after they take on golf as their profession account for sixty percent, and 20 percent of them even have a cycle of less than six months. Sense of belonging is greatly lost. Staff turnover happens especially in middle-low level of the management staff and grass roots employees.

3.2 The selection of management level is not well-organized

Considering factors like the concept of shareholders for investment, the phase of club's development, the variety of management style, clubs fail to take education background, experience in the job market and capability into consideration when selecting the management group. Instead, people from other professions are recruited to the management level directly. They turn out to be inexperienced at some management problem, unable to lead a whole team, only good at over elevate employees at some department. Some departments are even influenced by the relationship of the top management, which result in the plainness, non-professionalization and thus case hidden danger for the operation of club.

3.3 The overall diathesis of practitioners is rather low, the management level is lack of experience, team spirits awareness is weak

The overall practitioners in China receive a rather limited education. Department manager, management level at executive range take golf as a career for a short time, the lack of an overall understanding for the career and the experience for management is insufficient leads to the confusion of many clubs and high rate of core staff turnover. The professional education in the grass roots employee is nearly zero, the education background are mostly concentrated on high school and middle school, the overall diathesis is rather low. Their knowledge of the operation in the club is limited, thus lack of the concept of taking the club as a whole and out of team spirits, they work like in a pipeline. Many unfavorable factors make the club trapped in a difficult position. Take Hunan as an example, over the six clubs that are now opening only one makes profit, the rest have flat revenue or have made a loss over years. To maintain the expenditure of the club, they turn to develop business on other affiliated products. Some even take resources for capital, becoming the by-industry of real estate industry, which is quite the opposite from the original intention of developing golf business.

4. Analysis on the reason of club practitioner's current situation

4.1 The administrators are anxious to achieve quick success, emphasizing on short-term benefits and ignore the administration inside the club

As the main benefit-related staff in the club, the club administrators and the investors are in a principal-agent relationship, the income of administrators is directly related to their performance. With the principle of "Bounded Rational People", administrators tend to put the focus of management on the development of external market of clubs, concentrating on the sales of membership. The emphasis on short-term profits will definitely pay at the cost of overlooking the 
long-term sustainable development and the construction of corporation culture. The absence of humanistic concern and the simple, rude management with the unlimited sales of membership in daily work, finally lead the company to the overdraft of company's market value and credit and the passive situation of employees' high turnover.

4.2 The imperfection of the payment system and the big gap between incomes lead to brain drain.

In Maslow's hierarchy of needs, material income has always been the foundation and the essential part. When personal material needs are not met, other higher needs are not worth mentioning. According to the research on income of all levels in club, the income level gap between the decision-making level, higher management level (higher than the position of a department manager) and the lower management, executive level is especially big. The satisfaction degree towards payment also turns out to be quite the opposite. The difference of payment allocation is the origin of the intense relationship between colleagues and conflicts. The means of allocation in most clubs at present is a system that combines fixed payment plus another sum of money related to employee's work performance. This has activated employee's enthusiasm to so extent, but the problem of different standard for allocation and non-transparency of the payment system still existed.

4.3 The imperfection of golf education system and the variety of diathesis of professionals make it hard to meet the market's need.

In nearly ten years, a hundred and more training institutions were springing up nationwide in reaction to the market demand. Among them, 57 offer a degree for trainees. While within the limit of related policy of China, there is no major for golf in the list published by ministry of education. This leads to the dilemma that related universities are restricted by the limit of majors at the beginning of enrolling new students. Many universities name their majors as Business Management, Tourism Management, Social Sports Science, Leisure Sports, etc. to avoid treading the fine line, but after the enrollment, they would give golf education under those majors. But with the limit of professional titles, the making of talent training plan, selection of courses and the constitution of teaching program are constrained by the inborn deficiency. Compared to the solid golf education in foreign countries, we are bothered by force majeure. And as the same time popularity of golf in China is rather low, professionals who are familiar with objectives of teaching and the practical golf management are rare. So for the golf education time being in an experimental phase. What's more, some illegal training institutes recruit students with false promotion of saying golf professionals are equal to high-payment people. But in fact they are doing an education of “Three Rely-On”, that is, rely on cheating students, rely on teaching by coach, rely on the employment of internship. All the unfavorable factors contributed to the confusion in the golf training market. The so-called golf related professionals educated by universities are lack of competitiveness. Remarks on them in the profession low and their potential is also not high.

5. Enlightenment of golf practitioners' current status has on golf professionals education in China

5.1 The training of professionals is led by need of market and should be multi-leveled, multi-standardized

The standardization of golf professionals is a tendency under the adjustment of market discipline. In the aspect of the level and standard of talent training, focus should be put on the possibility of employment with the premise of in accordance with related principles released by ministry of education. Combine the practical need of club, theory and practice, put focus on the professional diathesis and integrated ability. Such as Golf Industry Management and Golf Course Management in Business Administration Department, Shenzhen University emphasizes the sales ability and practical ability of golf course construction. Zhuhai college of Jilin University encourages students strengthen the accomplishment of golf competition judgment. Social sports department and business management in Hunan International Economics University have additional course of golf sports and management. Meanwhile it is divided into golf sports, golf management and golf law maintenance to cultivate students in different aspects. All successful case studies 
mentioned above set example for the training of golf professionals in China and lead a new way.

5.2 The diversity of talent training model

In the aspect of professional training, because of the diversity in market demand, related training institutes should pay special attention to the quality of the training and resource integration. Meanwhile, they should cooperate with clubs to produce talents that are adapted to the demand of golf industry. So the diversity in training model is a natural result to catch with the development. At present, the "Degree + Qualification" and "2+2" practical management training model in Golf Centurial union class of Beijing University of Physical Education (The first years learning professional physical education, the remaining two years learning practical knowledge and take internship at clubs). Hunan International Economics University, Zhuhai College at Jilin University and Shenzhen University make division in the aspect of golf professional training, not only ensure the proficiency of training but also hole the faith of "Practice speaks the truth". They adopt the " $3+1$ " training model (The first three years learning professional physical education, the last years enter the club which they've signed a contract with, and then take training by spells). This model enhanced sense of responsibility, cooperation ability and strain capability of professionals. The post professional skills training at other vocational schools also helped solving the intense situation of recruitment at grass roots level in many clubs. In conclusion, develop professional training at the requirement of golf industry's demand is the way lead to virtuous cycle of "Everybody was let to display his talents fully, mutual benefit”.

5.3 Improve the hardware and software facilities and cultivate applicable talents with up-to-date method

As exotica, golf has not been in China more than thirty years, and has just been widely known by people for more than ten years. So as mentioned before, the qualification of teachers is far behind other traditional majors. For the time being, golf education talents in Chinese golf training institutes who have a degree in golf are rare, and most of them just switch to golf without solid professional knowledge. It is also the case with many universities. So, the construction of teacher's qualification should put emphasis on "Attract new recourse and relate to practice". Related personnel should have close contact with club and have practical experience, so as to work out practical training plans to guide the direction of students' learning. As for hardware facilities, sufficient teaching ground and related teaching facilities must be ensured. Organize students to have practices and competition, courage them to take short-term internship in clubs in winter and summer holidays are necessary. These enable teaching to catch up with the practical need of society, facilitate the combination of theory and practice.

5.4 Doing career planning during the process of education

Students in golf training are at the initial stage of professional skills learning, it's common to have vague profession cognition and unclear direction, which make them lack of systematicness and focus. Most students just follow the big trend and making no progress. When it comes to job hunting, they tend to be expecting more than they deserve. They are distressed when the post of grass roots level fail their own expectations of an ideal job, thus feel their sense of belonging can't be formed even for a long time. This is the main reason for the high turnover rate of professionals from half year to a year participated in the profession. Therefore an appropriate career planning in education plays an essential role in the sustainable development of students majored in golf. Various training institutes may also make career planning according to the types of talents to form an expectation of them own, thus help them to adjust themselves in different stages of their profession.

\section{References}

[1] Xiaoping Yu. Golf Class Series[M]. People Sports Press.2011.(2):140

[2] Kexiang Wu. Golf Club Management[M]. Nankai University Press.2009.2-4.

[3] Chao Xiang Group. Chao Xiang White Paper[R].Shenzhen.2010

[4] Baojun Wang. Talent Cultivation According to the Orders Benefits both Universities and Enterprises[J]. Chinese Vocational Technology Education, 2007,(18):32-33 